unable to acidify their urine a few days after aamission in "euglycaemic ketoacidosis" but more formal studies performed when they were metabolically stable failed to show any defect of $\mathrm{H}^{+}$and $\mathrm{NH}^{+}$excretion. Whatever the aetiology, the young age of the patients suggests an ability to "grow out" of the tendency.

The patients' mental alertness and in most their ability to walk into hospital, even when severely ketoacidotic, supports the concept that clouding of consciousness is unrelated to the severity of the ketoacidosis but is dependent on severe hyperglycaemia and hyperosmolarity (Gerich et al., 1971).

The principles of treatment are to correct fluid and electrolyte loss and to re-establish carbohydrate metabolism. The former is often trivial, resulting largely from the vomiting, but because of the latter intravenous therapy with modest quantities of potassium, sodium, and water is usually required. Nevertheless, sufficient exogenous glucose must also be given to restore normal cellular utilization and thus reverse the ketoacidosis. Normal saline should therefore be avoided and dehydration corrected with $5 \%$ dextrose/saline and $5 \%$ dextrose. When the blood glucose is low in the absence of clinical dehydration $10 \%$ dextrose may be required. It has been recommended that the dose of insulin should be proportional to the blood glucose level (Sheldon and Pyke, 1968) but this is clearly inappropriate in these "euglycaemic" patients who may require large quantities of insulin to correct their severe ketoacidosis. Response to therapy is assessed very largely by the serum bicarbonate which after four to five hours should begin to rise fairly rapidly, irrespective of whether or not bicarbonate has been administered.

Though the liberal use of bicarbonate has been recommended
(Addis et al., 1964) others have suggested a more cautious approach (Zimmet et al., 1970). We avoided giving bicarbonate except in those patients with recurrent admission in whom we suspected there could be a renal tubular dysfunction. By correcting the extracellular acidosis without influencing the causal inadequate cellular utilization of glucose, the excessive use of alkali may produce injurious disequilibrium between the intracellular and extracellular pH (Posner and Plum, 1967).

The department's policy of encouraging diabetics to adjust their own dose of insulin may, in part, be responsible for our not uncommon experience of euglycaemic ketoacidosis, which has previously attracted very little attention. These patients form one end of the broad spectrum of diabetic metabolic decompensation but are of therapeutic importance because with appropriate management biochemical death should not occur.

\section{References}

Addis, G. J., Thomson, W. S. T., and Welch, J. D. (1964). Lancet, 2, 223. Campbell, I. W., Munro, J. F., and Duncan, L. J. P. (1973). In press.

Duncan, L. J. P. (1971). In Textbook of Medical Treatment, ed. S. Alstead, A. G. McGregor, and R. H. Girdwood, 12th edn. p. 334. Edinburgh, Churchill Livingstone.

Gerich, J. E., Martin, M. M., and Recent, L. (1971). Diabetes, 20, 228.

Posner, J. B., and Plum, F. (1967). New England fournal of Medicine, 227,

Sheldon, J., and Pyke, D. A. (1968). In Clinical Diabetes and its Biochemical Basis, ed. W. G. Oakley, D. A. Pyke, and K. W. Taylor. Chapt. 17. Oxford, Blackwell Scientific.

Zimmet, P. Z., Taft, P., Ennis, G. C., and Sheath, J. (1970). British Medical Fournal, 3, 610 .

\title{
Hand Carriage of Gram-negative Bacilli and Staphylococcus aureus
}

\author{
JOHAN N. BRUUN, CLAUS O. SOLBERG
}

British Medical fournal, 1973, 2, 580-582

\section{Summary}

The influence of hexachlorophane disinfection on the bacterial hand flora of hospital personnel has been examined. Hexachlorophane effectively reduced the total number of bacteria and the staphylococcal carriage. Gram-negative bacilli were isolated from $18.8 \%$ of the personnel, and $13 \%$ of the carriers continued to carry Gram-negative bacilli for more than six months. The carrier rate was significantly higher among those using hexachlorophane detergents $(20.8 \%)$ than among those using plain soap (14.1\%). Prolonged hand carriage of Gram-negative bacilli was often associated with skin irritation, especially of the nailfolds. Hand carriage may be an important source of Gram-negative infections in hospital, and the increase in these infections may partly be due to extensive use of hexachlorophane preparations.

University of Bergen, School of Medicine, Medical Department B, N-5000 Bergen, Norway

JOHAN N. BRUUN, M.D., Assistant Physician

CLAUS O. SOLBERG, M.D., Associate Professor of Medicine

\section{Introduction}

Infections acquired in hospitals are usually caused by Gramnegative bacilli or Staphylococcus aureus (Adler et al., 1971; Williams et al., 1966), and transmission by the hands of hospital personnel is regarded as one of the most important routes of cross-infection (Juhlin and Ericson, 1965; Mortimer et al., 1966; Salzman et al., 1968; Adler et al., 1970). Previously we documented that treatment of surgical patients and personnel with hexachlorophane containing detergents effectively reduced the transmission of staphylococci and the prevalence of postoperative staphylococcal infections (Bruun, 1970). In nurseries, however, the extensive use of these preparations has been incriminated as the cause of increasing Gram-negative bacillary infections (Forfar et al., 1968; Light et al., 1968).

In the present study it was shown that a significant number of hospital personnel carried Gram-negative bacilli on their hands. The duration of this carriage and the effect of long-term use of a hexachlorophane detergent on the bacterial hand flora are reported.

\section{Material and Methods}

The bacterial hand flora of the ward personnel (nurses and nurses' aides) in three departments at Haukeland Hospital, Bergen, Norway, was examined. Samples were obtained during two periods with six-months in between. During each period 
TABLE I-Bacterial Hand Flora of Hospital Personnel using Bar Soap or a Hexachlorophane Detergent

\begin{tabular}{|c|c|c|c|c|c|c|}
\hline \multirow{2}{*}{\multicolumn{2}{|c|}{ Department }} & \multirow{2}{*}{ Period } & \multirow{2}{*}{$\begin{array}{l}\text { Hand Washing Preparation } \\
\text { (No. of Samples) }\end{array}$} & \multicolumn{2}{|c|}{$\%$ Isolation Rate } & \multirow{2}{*}{$\begin{array}{l}\text { Total No. of } \\
\text { Organisms per Sample } \\
\text { (Mean Log Count) }\end{array}$} \\
\hline & & & & $\begin{array}{c}\text { Gram-negative } \\
\text { Bacilli }\end{array}$ & Staph. aureus & \\
\hline $\begin{array}{l}\text { Medical department B } \\
\text { Surgical department A } \\
\text { Surgical department B }\end{array}$ & $\begin{array}{r}\cdots \\
\ldots \\
\ldots\end{array}$ & $\begin{array}{l}1 \\
2 \\
1 \\
2 \\
1 \\
2\end{array}$ & $\begin{array}{l}\text { Bar soap (78) } \\
\text { Bar soap (75) } \\
\text { Bar soap (81) } \\
\text { Hexachlorophane detergent (157)* } \\
\text { Hexachlorophane detergent (159)* } \\
\text { Hexachlorophane detergent (74) }\end{array}$ & $\begin{array}{l}15 \cdot 4 \\
13 \cdot 3 \\
13.6 \\
21 \cdot 0 \\
20 \cdot 1 \\
21 \cdot 6\end{array}$ & $\begin{array}{l}\overline{12 .} \cdot 0 \\
21 \cdot 0 \\
10.2+ \\
13.8 \ddagger \\
10.8\end{array}$ & $\begin{array}{l}5 \cdot 71 \\
5 \cdot 77 \\
5 \cdot 35 \\
5 \cdot 19 \\
4 \cdot 42 \\
5 \cdot 11\end{array}$ \\
\hline
\end{tabular}

*The personnel were examined twice during the period.

+ The difference from period 1 is significant $(P<0.05)$

$\ddagger$ Based on 80 samples. Only one sample from each subject was examined for the presence of Staph. aureus.

the personnel of medical department $B$ used plain bar soap for hand washing. In surgical department $A$ bar soap was used during the first period and a 3\% hexachlorophane detergent solution was used during the second period. In surgical department $B$ the hexachlorophane detergent was used during both periods.

Carriers of Gram-negative bacilli were re-examined two weeks after the first sample, and persistent carriers of Gramnegative bacilli were followed with regular samples. The sampling technique was a modification of the method described by Lowbury and Lilly (1960). The subjects washed their hands for one minute in a standard way using sterile bar soap. The hands were dried and the "resident flora" was examined using a two-minute, standardized hand-washing procedure with $300 \mathrm{ml}$ of sampling fluid (Bruun et al., 1968). To neutralize the antibacterial effect of hexachlorophane Tween $80(1 \%)$ was added to the sampling fluid. Dilutions of the sampling fluid were inoculated on blood agar, lactose agar, and mannitol salt agar plates. The total number of bacteria and the number of Gramnegative bacilli and Staph. aureus were recorded.

\section{Results}

In medical and surgical departments $B$ only minor differences between the two periods in isolation rates for Gram-negative bacilli and staphylococci were observed (table I). In surgical department A the isolation rate for Staph. aureus was significantly reduced from $21.0 \%$ when bar soap was used to $10.2 \%$ in the hexachlorophane detergent period (table I). Simultaneously the isolation rate for Gram-negative bacilli increased from 13.6\% to $21.0 \%$. This difference is not significant. When all counts obtained during the hexachlorophane periods were compared with counts from bar soap periods, however, a significantly higher isolation rate for Gram-negative bacilli was found in the hexachlorophane group (table II). The mean log counts of bacteria were considerably lower in the groups using the hexachlorophane detergent than in those using bar soap (tables I and II). The reduction of the overall mean log count from 5.60 to 4.86 represents an $80 \%$ reduction in the absolute count. Thirty-five per cent. of the carriers of Gram-negative bacilli had more than one type of these organisms. Lactosefermenting coliforms constituted $56 \%$ of the isolates, $32 \%$ were "other coliforms," 9\% Proteus strains, and 3\% Pseudomonas aeruginosa.

Gram-negative bacilli were isolated from 110 staff members $(18.8 \%$ of the samples). Two weeks later a second sample was obtained from 106 of the 110 staff members, and Gramnegative bacilli were isolated from 56. A third sample was obtained from 32 of the 56 staff members and eight were carriers. These subjects continued to carry Gram-negative bacilli for 6-20 months. From these results it may be estimated that $13 \%$ of those originally having Gram-negative bacilli on their hands were persistent carriers for periods of more than six months. All the persistent carriers had used the hexachlorophane detergent, six throughout the whole study and two for shorter periods. Identical strains were isolated throughout this
TABLE II-Effect of Hexachlorophane Disinfection on Bacterial Hand Flora of Hospital Personnel (Numbers of Samples are given in Parentheses)

\begin{tabular}{|c|c|c|c|}
\hline \multirow{2}{*}{$\begin{array}{l}\text { Preparation used for } \\
\text { Hand Washing }\end{array}$} & \multicolumn{2}{|c|}{ \% Isolation Rate } & \multirow{2}{*}{$\begin{array}{l}\text { Total No. of } \\
\text { Organisms } \\
\text { per Sample } \\
\text { (Mean Log Count) }\end{array}$} \\
\hline & $\begin{array}{c}\text { Gram-negative } \\
\text { Bacilli }\end{array}$ & Staph. aureus & \\
\hline $\begin{array}{l}\text { Ordinary bar soap } \text {. . }_{\text {Hexachlorophane detergent }} \\
\text {. }\end{array}$ & $\begin{array}{l}14 \cdot 1 *(234) \\
20 \cdot 8 *(390)\end{array}$ & $\begin{array}{l}16 \cdot 7(156) \\
11 \cdot 3(311)\end{array}$ & $\begin{array}{l}5.60(234) \\
4.86(390)\end{array}$ \\
\hline Total & $18 \cdot 8 \quad(624)$ & $13 \cdot 1(467)$ & $5 \cdot 14(624)$ \\
\hline
\end{tabular}

*The difference from ordinary bar soap is significant $(P<0.05)$.

TABLE III-Bacterial Hand Flora of Carriers of Gram-negative Bacilli during Treatment with Antibacterial Preparations

\begin{tabular}{|c|c|c|}
\hline $\begin{array}{l}\text { Preparation used for Hand Washing } \\
\text { (Active Ingredient) }\end{array}$ & $\begin{array}{l}\text { Mean Count of } \\
\text { Gram-negative } \\
\text { Bacilli }\end{array}$ & $\begin{array}{l}\text { Mean Bacterial } \\
\text { Count }\end{array}$ \\
\hline \multirow{2}{*}{ 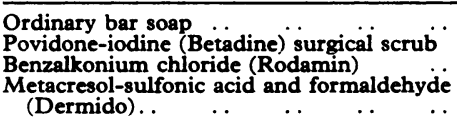 } & $\begin{array}{l}323,500^{*} \\
655,500^{*} \\
986,900 \dagger\end{array}$ & $\begin{array}{r}856,100^{*} \\
1,068,000^{*} \\
1,791,700 \dagger\end{array}$ \\
\hline & $164,100 \ddagger$ & $425,000 \ddagger$ \\
\hline
\end{tabular}

* Mean of 8 counts from 4 subjects.

+ Mean of 6 counts from 3 subjects.
$\ddagger$ Mean of 4 counts from 2 subjects.

period from six carriers; two persistent carriers changed strains during the study. Skin irritation and signs of paronychia with redness and swelling of the nailfolds were present in five persistent carriers for most of the investigation period. Only one, however, had purulent discharge lasting a few days. Separate samples obtained from various areas of the hands showed the majority of Gram-negative bacilli to be confined to the diseased skin.

In four carriers, three with paronychia, the effect of replacing the hexachlorophane detergent with agents thought to be more active against Gram-negative bacilli was studied (table III). Each agent was used for two weeks with a two-week interval with bar soap. The disinfectants were used for all hand washing -at least five times daily. The hand flora was examined after treatment for one and two weeks respectively. No significant decrease in bacterial counts was observed (table III). After the completion of this experiment two subjects with paronychia were treated twice daily with Onychophytex (Løvens Kemiske Fabrik, Copenhagen; borogallic acid $7.5 \%$, salicylic acid $0.8 \%$, acetic acid $10 \%$, and benzylic oxybenzoate $0.34 \%$ in alcoholic ethylacetate). Each showed a significant decrease in the number of Gram-negative bacilli within one week (mean count reduced from 189,400 to 5,500 per sample), and in one of these subjects the bacilli were eliminated within one month. The other still gave small numbers of organisms in hand-washings after treatment for six weeks.

\section{Discussion}

The efficacy of hexachlorophane detergents is greatly increased 
when used several times daily (Lowbury and Lilly, 1960; Weatherall and Winner, 1963; Williams et al., 1966), and some authors have questioned the effect of these preparations used only when personnel are on duty (Lowbury and Lilly, 1960; Weatherall and Winner, 1963). The present investigation, however, confirms the observation of Wilson (1970) that use only on duty effectively reduces the number of bacteria and the prevalence of staphylococci on the hands.

In previous studies Gram-negative bacilli have frequently been isolateil from the hands of hospital personnel (Salzman et al., 1968; Adler et al., 1970). These bacteria, however, have usually been regarded as transient organisms which could easily be removed by washing with soap and water (Lowbury et al., 1964; Brodie, 1965). In our study $18 \cdot 8 \%$ of the personnel carried Gram-negative bacilli on their hands after washing thoroughly for one minute; the majority were carriers for more than two weeks, and some subjects were persistent carriers for months, perhaps years. The results of our study, therefore, strongly indicate that the Gram-negative bacilli should be regarded as frequent members of the resident flora.

Hexachlorophane is less effective against Gram-negative bacilli than Gram-positive organisms (Williams et al., 1966), and the extensive use of these preparations for washing babies has been incriminated as the cause of increasing colonization and infection with Gram-negative bacilli among newborns (Forfar et al., 1968; Light et al., 1968). The results of the present study suggest that the routine use of these agents for hand disinfection by hospital personnel may promote colonization of the hands with Gram-negative bacilli, and it seems possible that the extensive use of hexachlorophane detergents may contribute to the recent increase in Gram-negative hospital infection (Bruun, 1970; Wilson, 1970). When staphylococcal infections represent a major problem, however, the danger of increasing the prevalence of Gram-negative bacilli should not prohibit the use of hexachlorophane detergents (Bruun, 1970).

In our study persistent carriage of Gram-negative bacilli was usually related to the presence of skin irritation or paronychia, and large numbers of bacilli were isolated from the skin lesions. Failure of antiseptics to reduce the number of bacteria during hand washing may have been due to the location of the bacteria deep in the skin layers. Nevertheless, during treatment of the paronychia with Onychophytex, which was applied to the lesions after hand washing, a marked reduction in the number of Gram-negative bacilli was shown. Search for skin lesions should therefore be included in the routine surveillance of hospital infections, and even minor lesions should be cultured and treated with a local application of effective antiseptics.

\section{References}

Adler, J. L., Shulman, J. A., Terry, P. M., Feldman, D. B., and Skaliy, P. (1970). Fournal of Pediatrics, 77, 376.

Adler, J. L., Burke, J. P., and Finland, M. (1971). Archives of Internal Medicine, 127, 460 .

Brodie, J. (1965). Scottish Medical Fournal, 10, 115.

Brodie, J. (1965). Scottish Medical fournal, 10, 115.
Bruun, J. N. (1970). Acta Medica Scandinavica, Suppl. No. 514.

Bruun, J. N. (1970). Acta Medica Scandinavica, Suppl. No. 514. 184, 417 .

Forfar, J. O., Gould, J. C., and Maccabe, A. F. (1968). Lancet, 2, 177.

Juhlin, I., and Ericson, C. (1965). Fournal of Hygiene, 63, 35.

ight, I. J., Sutherland, J. M., Cochran, M. L., and Sutorius, J. (1968). New England fournal of Medicine, 278, 1243.

Lowbury, E. J. L., and Lilly, H. A. (1960). British Medical fournal, 1, 1445 Lowbury, E. J. L., Lilly, H. A., and Bull, J. P. (1964). British Medical Fournal, 2, 531 .

Mortimer, E. A., Wolinsky, E., Gonzaga, A. J., and Rammelkamp, C. H. (1966). British Medical fournal, $1,319$.

Salzman, T. C., Clark, J. J., and Klemm, L. (1968). Antimicrobial Agents and Chemotherapy-1967, p. 97. Ann Arbor, Michigan, American and Chemotherapy-1967,

Weatherall, J. A. C., and Winner, H. I. (1963) Fournal of Hygiene, 61, 443.

Weatherall, J. A. C., and Winner, H. I. (1963). Fournal of Hygiene, 61, 443. Hospital Infection. Causes and Prevention. London, Lloyd-Luke.
Hond

Wilson, P. E. (1970). fournal of Applied Bacteriology, 33, 574.

\title{
Oral Glucose Tolerance and Hormonal Response in Heroin-dependent Males
}

\author{
J. L. REED, A. H. GHODSE
}

\section{Introduction}

It is part of the folk-lore of narcotic addiction that an addict has a craving for sweet foods, and observation of the eating patterns of heroin-dependent patients attending a drug dependency treatment unit suggested that they have a preference for food containing a high proportion of carbohydrate.

It has also been part of the mythology of addiction that diabetes mellitus is more frequent among heroin addicts than other people. A survey of patients at the National Institute of Mental Health Addiction Research Centre, Lexington, U.S.A. (Sapira, 1968) showed that of 900 patients only one was diabetic, which suggests an incidence certainly no higher than that in the normal population. Chopra and Bose (1930), investigating an Indian belief that opium was beneficial for diabetes mellitus, found that in mild cases daily doses of $60-360 \mathrm{mg}$ of opium produced a reduction of sugar in, or disappearance of sugar from, the urine. The blood sugar was not affected and it was suggested that one of the constituents of opium might influence the renal threshold for glucose. Desser and Arvin (1969) reported diabetic ketoacidosis occurring during acute heroin abstinence.

We report the results of some preliminary investigations on carbohydrate absorption and consequent hormonal release in 12 chronically heroin-dependent patients and 12 normal controls.

J. L. REED, M.R.C.P., M.R.C.PSYCH., Senior Lecturer, and Consultant Psychiatrist at Hackney Hospital

A. H. GHODSE, M.D., Research Worker, and Honorary Registrar at Hackney Hospital 